\title{
Mathematical Simulation Of Adaptive Allocation Of Discrete Resources
}

\author{
Anisimov E.G. \\ Department of Science and Information \\ Russian customs academy \\ Lyubertsy town, Moscow Region, Russia
}

Sonkin M.A.

Institute of Cybernetics

National research Tomsk Polytechnic University

Tomsk, Russia

sonkin@tpu.ru

\author{
Anisimov V.G. \\ Department of Informational Systems in \\ Economics and Management \\ Peter the Great St.Petersburg Polytechnic University \\ St. Petersburg, Russia
}

\begin{abstract}
The dynamic and uncertainty of management system generate and complicate the problem of providing appropriate quality management solutions. Optimization and adaptive approach to the process of taking a management decision is one the most effective. Practically, it can be implemented by modeling adaptive distribution of discrete resources. So, the results of this article include the methods of forming mathematical models of distribution of discrete resources, based on the principle of optimization and adaptive approach to the process of taking a management decision in automated information management systems in the real-time mode (AIMS). The implementation of considered methods help to scrutinize such aspects of a real management system as dynamics and uncertainty of situations, but at the same time to operate with simple mathematical models of static optimization for taking a decision about the distribution of resources.
\end{abstract}

Keywords - management system, discrete resources, distribution of resources, uncertain circumstances, adaptation, optimization, model

\section{INTRODUCTION}

Effective distribution of resources is one the most common task in Automated Information Management System (AIMS). Within this framework, one of the most important categories is the optimal distribution of discrete resources [1-5]. For the realtime mode AIMS the allocation of resources present a multistaged process $[6,7]$. Each stage of the process includes featuring certain resources for fulfillment of arose needs by that moment.

At present there are many accurate researches on cases with determined needs, predicted emerge time and available resources [7 - 10]. So, featuring management solutions in AIMS is usually based on optimization approach to the resources distribution task [11-14].

Applying optimization methods for development of complex systems with known set of criteria and allocation of managed resources allow us to solve the problem of modeling systems in real time mode [15] and accomplish of the adaptive control problem with a limited number of actions [16].

However, there is a deductive uncertainty of volume, the nature and availability of resources, time of their emerging, which is appropriate for any real management system [16]. Moreover, taking into account the consequences of each decision in the multistaged process force to find ways for implementing optimization adaptive principle of forming a management solution in AIMS [10,17]. This article is focused on developing methodical thesis of mathematical modelling based on this principle for discrete resources allocation.

\section{MODEL'S STRUCTURE}

The background of suggested approach for forming models based on optimization adaptive principle for the process of taking a management solution about discrete resources allocation in real-time mode includes the functional scheme of AIMS as a process within a system $\mathrm{S}$ (fig.1) which consists of four subsystems- demand, information, management and resources systems.

At the same time, the demand system includes objects forming resources needs. Information system identifies the needs and forms the list of necessary resources. The resources system prepares and uses the resources during the allocation process.

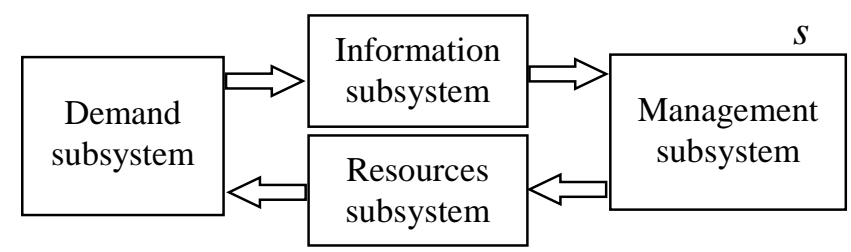

Fig. 1. The system's generalized scheme

During the process of resources utilization a positive effect on the operating system $\mathrm{S}$ appears. 
The solution of resource allocation is formed by the management system in the means of sequence of the local decisions making in the moments of time that are indefinite in advance $t_{k}, k=1,2, \ldots$, and meet a requirement

$$
t_{0}<t_{1}, t_{2}, \ldots t_{k} \ldots<T,
$$

where $t_{0}$ is the start point, $T$ is the final point AIMS system activity.

Every local decision is approved with consideration of the current situation on the base of the processing data about $\psi_{S}$ system $S$ and its substance changes the future forecast. The content of such decision is the appointment of the available recourses at the time $t_{k}$ for mature the needs of system elements - consumers of resources at this moment. Previously adopted decisions have an impact on this decision because they determine the presence and type of resources and the demand for them. In its turn decision adopted in the moment of time $t_{k}$ significantly affects the decisions that may be taken in the next moments $t_{i}, i>k$.

Formally, the range of possible decisions for this can be represented as a multitude:

$$
\begin{gathered}
V=\left\{V^{k}\right\}, k=1,2, \ldots,(1) \\
V^{k}=\left\|V_{i j}^{k}\right\|,(2)
\end{gathered}
$$

where $i=1,2, \ldots, I^{k}, j=1,2, \ldots J^{k}, k=1,2, \ldots$,

$V_{i j}^{k}$ - is the amount of the $i$-type resources, allocated to meet the needs of the $j$-th object in the $t_{k}$ moment of the security system functioning;

$I^{k}$ - is the amount of recourses of all types that are available to the functioning of security system at $t_{k}$ moment;

$J^{k}$ - is the quantity of the elements in the security system that creates demand for resources at the moment $t_{k}$.

The implementation of optimal adaptation during the process of taking a solution about resource allocation in certain cases is based on forming appropriate model with a basic structure of the following type.

For example, it's needed to define the type of allocation:

$$
V^{k *}=\left\|V_{i j}^{k *}\right\|,(3)
$$

where $i=1,2, \ldots, I^{k}, j=1,2, \ldots J^{k}, k=1,2, \ldots$,

so, that ensures the fulfillment of next conditions:

$$
\begin{gathered}
Q\left(V^{k *}\right)=\max _{V^{k} \in V} Q\left(V^{k}\right),(4) \\
\Delta Q_{i j}>u_{i}^{k}\left(\psi_{S}\right),(5)
\end{gathered}
$$

with the following restrictions:

$$
\sum_{j=1}^{J_{k}} V_{i j}^{k}<M_{i}^{k},(6)
$$

where $=1,2, \ldots, i=1,2, \ldots, I^{k}, j=1,2, \ldots J^{k}$;

$k$ is phase ID of the security system (at time moment $t_{k}$ );
$Q\left(V^{k}\right)$ - is expected effect of the resource allocation in accordance with the allocation version $V_{k}$;

$\Delta Q_{i j}$ - is the increment of the function $Q\left(V^{k}\right)$ in case of additionally identity of recourses by $i$-type means to the plan $V_{k}$ for meeting demand of $j$-th object;

$u_{i}^{k}\left(\psi_{S}\right)-$ is the level of specific value for $i$-type resources using that ensures maximum efficiency from possible resources using managed $S$ - system for the entire period $\left[t_{k}, T\right]$;

$\psi_{S}$ - is a multitude process parameters of the system $S$, affecting the efficiency of resource use,

$M_{i}^{k}$ - is the amount of $i$-type resource dispensed at $t_{k}$ point of time ( $k$-th phase of security system activity.

In the above model structure, the equation (3) indicates that optimal plan of the resource allocation is generated as a sequence of local decisions $V^{k *}$ and exposes the contents of each local decision in a matrix whose elements are the volume of resources allocated to meet the needs of the relevant objects. It's useful to note, that decisions $V^{k *}$ taken in some, not necessarily a predefined, time points functioning of the system $t_{k}$.

The equation (4) reflects demand of the most complete use of the system capability to get the maximum effect at each stage of resources using process.

The equation (5) prevents local optimization of resource allocation from maximum global effect during the whole process of system functioning. It is a criteria for the selection of the many possible options for the current phase of the allocation of resources such subset, choice of which is not contrary to the achievement of the global optimum taking into account not only the current situation at this point, but the results of predicting its future development. Therefore it provides for adaptation of the process to the folding conditions of AIMS.

The equation (6) reflects the balanced limits on the number of the distributed resources of each type.

Specific resource allocation models, realizing the proposed approach, is obtained by the explicit representation of the dependences included in the model (3) - (6). Exact models of resource allocation, based on suggested approach, are formed by formalizing the relations of this system. The options of such formalizing for various fields are analyzed in [7-9]. Usually these models are NP-difficult [10].

\section{METHOD OF THE ADAPTATION RATES DETERMINATION}

In the model (3) - (6) the possibility of local and global optima coordination where decision-making on the allocation of resources is provided by the introduction of the condition (5). The full constructive representation of it requires vector construction:

$$
U^{k}\left\|u_{i}^{k}\left(\psi_{S}\right)\right\|,(7)
$$

where $i=1,2, \ldots, I^{k}, k=1,2, \ldots$ 
At the core of definition of this vector components is the principle of separation of many possible distributions of the available resources at time $t_{k}$, subset of valid variants. The choice of distributions should not lead to decrease in the expected maximum effectiveness of these resources, taking into account existing and expected before the end of the reporting phase of the system needs. These components are a lower limited on the specific effectiveness of available resources at the decision point. Levels restrictions $u_{i}^{k}\left(\psi_{S}\right)$ should be determined by taking into account all available information about the current values and trends of the parameters of the state system $S$ at each step of the allocation.

The choice of mentioned restrictions as the parameters of adaptation is driven by the fact that specific efficiency of utilization system's resources is invariant with respect to a particular embodiment, the distribution characteristic of the effectiveness of their use is consistent with the typical structure of the model of discrete programming, and thus relatively easy to predict.

Taking into consideration previously discussed schematic modeled resource allocation process in the system $S$ in the time interval $\left[t_{k}, T\right]$ the formation of the resource demand can be viewed as a set of flows of demands with rate $\lambda_{i 0}^{k}$. Informative managed subsystem estimates the expected specific efficiency of using different types of available resources and provides the selection criteria of flow requirements (5), thereby forming the streams of "acceptable" needs. The relation below determines the intensities of these flows

$$
\lambda_{i}^{k}\left(u_{i}^{k}\right)=\lambda_{i 0}^{k} \int_{u_{i}^{k}}^{\max q_{i}^{k}} \varphi_{i}\left(q_{i}^{k}\right) d q_{i}^{k},(8)
$$

where $i=1,2, \ldots, I^{k}, k=1,2, \ldots$;

$q_{i}^{k}$-is specific efficiency of $i$-type resource using on the $k$ stage of the security system;

$\max q_{i}^{k}-$ is the upper limit of the specific resource efficiency;

$\varphi_{i}\left(q_{i}^{k}\right)-$ is the probability density function of the parameter $q_{i}$

When the streams $\lambda_{i}^{k}$ are forming, parameters $u_{i}^{k}$ provides some vacuum of input flow of resource needed. If these magnitudes are small, then all available resources can be used also at low efficiency. This leads to increasing risk in shortage of appropriate resource in the future, when its application would be more expedient. If the values $u_{i}^{k}$ too high, then the risk of not using appropriate resources because of their loss or the lack of suitable facilities for their use.

The issue is to choose the optimal parameters $u_{i}^{k}, i=$ $1,2, \ldots, I^{k}, k=1,2, \ldots$, which would provide the maximum value of the expectation of resource use efficiency in the operation of the system $\mathrm{S}$ adjusted for these risk factors.
If the $u_{i}^{k}$ value fixed at some stage of distribution, the expected specific effectiveness of resources is characterized by the probability density:

$$
f_{i}\left(q_{i}^{k}, u_{i}^{k}\right)=\varphi_{i}\left(q_{k}^{i}\right) /\left[1-\int_{\min q_{i}^{k}}^{u_{i}^{k}} \varphi_{i}\left(q_{i}^{k}\right)\right],(9)
$$

where $i=1,2, \ldots, I^{k}, k=1,2, \ldots$;

$\min q_{i}^{k}-$ is the lower limit for the value of $q_{i}^{k}$.

Taking into account (9) the mathematical expectation of a specific resource use efficiency is defined by:

$$
q_{i}^{* k}\left(u_{i}^{k}\right)=\int_{u_{i}^{k}}^{\max } q_{i}^{k} q_{i}^{k} f\left(q_{i}^{k}, u_{i}^{k}\right) d q_{i}^{k},(10)
$$

where $i=1,2, \ldots, I^{k}, k=1,2, \ldots$

Moreover, if resources in operation process of concerned system $S$ is not renewed, expected overall effect resulting from their use, taking into account expression (10), can be calculated by the formula:

$$
Q^{k}\left(U^{k}\right)=\sum_{i=1}^{I^{k}} \sum_{m=0}^{r_{i}^{k}} m F_{i m}^{k}\left(q_{i}^{* k}, u_{i}^{k}\right) q_{i}^{* k}\left(u_{i}^{k}\right),
$$

where $k=\overline{1, K}, r_{i}^{k}-$ is the amount of $i$-type resources, allocated on $k$-stage of the system $S$ operation process;

$F_{i m}^{k}\left(q_{i}^{* k}, u_{i}^{k}\right)$ - is the probability of intended use of $m$ - units of the $i$-type resource.

When resources are renewed during the system functional process, full-expected effect from their use with consideration to $(8,10)$ can be calculated by the following function

$$
Q^{k}\left(U^{k}\right)=\sum_{i=1}^{I^{k}} H_{i}^{k}\left(u_{i}^{k}\right) q_{i}^{* k}\left(u_{i}^{k}\right) \lambda_{i}^{k}\left(u_{i}^{k}\right)\left(T-t_{k}\right),
$$

where $k=\overline{1, K}$;

$H_{i}^{k}\left(u_{i}^{k}\right)$-is the possibility of intended use of one unit of the $i$-type resource.

The vector (7) have to maximize the efficiency use of allocated resources. According to (11), (12) determination of considered vector can be represent as solution of the following extremal case:

$$
U^{* k}=\left\|u_{i}^{* k}\right\|=\arg \max _{u_{i}^{k}} Q^{k}\left(U^{k}\right)(13)
$$

Further definition of (12) requires characterization of following functions: $\varphi_{i}\left(q_{i}^{k}\right), F_{i m}^{k}\left(q_{i}^{* k}, u_{i}^{k}\right), H_{i}^{k}\left(u_{i}^{k}\right)$. The solutions of these tasks are decribed in [12-14].

\section{CONCLUSION}

In general, the considered formalization of the discrete resources allocation and methods of mathematical stimulation in different AIMS in real-time environment allows taking into account such essential features of the real process as a dynamic and uncertain environment, and at the same time to be used for the decision-making of relatively simple static optimization instrument $[4,6,7]$. Herewith the planning process acquires the adaptive nature. 


\section{REFERENCES}

[1] Rao H.R. An information and preference theory approach to a discrete resource allocation problem. Automatica, 1991, Vol. 27 (5), pp. 837-843.

[2] Cassandras C.G., Julka V. Descent algorithms for discrete resource allocation problems. Proceedings of the IEEE Conference on Decision and Control, 1994, Vol. 3, pp. 2639-2644. DOI: 10.1016/00051098(91)90038-4

[3] Gazizov T.T. Synthesis of optimal wire antenna. Monography, Tomsk, Published by Tomsk state university of control systems and radioelectronics, 2013, 160 p. (in Russian)

[4] Anisimov V.G.,Anisimov E.G. A method of solving one class of integer programming problems. USSR Computational Mathematics and Mathematical Physics, 1989, Vol. 29(5). pp. 238-241. (in Russian)

[5] Alekseyev A.O., Alekseyev O.G., Anisimov V.G., Anisimov E.G. The use of duality to increase the effectiveness of the branch and bound method when solving the knapsack problem. USSR Computational Mathematics and Mathematical Physics, 1985, Vol. 25:№6, pp. 50-54. (in Russian)

[6] Czuchra W. Allocation of discrete resource in order transmission hierarchical organization. International Journal of Systems Science, 1988, Vol. 19 (11), pp. 2419-2426.

[7] Anisimov, V.G.,Anisimov, Ye.G A branch-and-bound algorithm for one class of scheduling problem// Computational Mathematics and Mathematical Physics, 1992, Vol. 32:№ 12. pp. 1827-1832 . (in Russian)

[8] Markov V.N. Construsction method of the vicinty of statistics in the problem of optimum of optium consumption non-renewable resources. Polythematic network electronic scientific journal of Kuban State Agrarian University, 2015, Vol.112, pp. 1331-1342.

[9] Bohez S., Verbelen T., Simoens P., Dhoedt B. Discrete-event simulation for efficient and stable resource allocation in collaborative mobile cloudlets. Simulation Modelling Practice and Theory, 2014, Vol. 50, pp. 109-129.

[10] Anisimov, V.G., Anisimov, E.G., Kapitonenko V.V. Optimization and adaptive approach to investment management in the face of uncertainty. Moscow, Publishing House of the Russian Customs Academy, 2009. 173 pp. (in Russian).

[11] Igumnov A.O., Sonkin D.M., Khrul S.A. Development of a Combined Algorithm for Request Distribution Using Multi-Objective Optimization Methods. Applied Mechanics and Materials, 2015, Vol. 756, pp. 646-651. DOI: 10.4028/www.scientific.net/AMM.756.646

[12] Anisimov, V.G., Anisimov, E.G Algorithm for the optimal distribution of discrete nonuniform resources on the web. Computational Mathematics and Mathematical Physics, 1997. Vol. 37. № 1. pp. 54-60.

[13] Anisimov, V.G.,Anisimov, E.G. Modification of the method for solving a class of integer programming problems. Computational Mathematics and Mathematical Physics, 1997. Vol. 37. №2. pp. 179-183. (in Russian)

[14] Anisimov V.G., Anisimov E.G., Matematicheskie modeli i metody v upravlenii razvitiem slozhnykh tekhnicheskikh sistem. - SPb.: Izd-vo «Politekhnika», 2004. (In Russian)

[15] Anisimov V.G., Anisimov E.G., Chernysh A.Ya., Chechevatov A.V. Optimizatsionnye modeli i metody $\mathrm{v}$ upravlenii innovatsionnymi protsessami. - Moskva: Izd-vo Rossiyskoy tamozhennoy akademii, 2006. (In Russian)

[16] Gazizov T.R., Melkozerov A.O., Gazizov T.T., Kuksenko S.P., Zabolockiy A.M. Computer simulation of complex structures conductor at Designing of television and computing systems. Izvestija vysshih uchebnyh zavedenij, Spb., Priborostroenie, 2005, Vol. 48 (11), pp.64-67. (in Russian)

[17] Khrul S.A., Sonkin D.M. Increasing positioning accuracy of moving objects using an adaptive algorithm based on diagnostic filtration. Life Science Journal, 2014, 11 (SPEC. ISSUE 11), art. no. 100, pp. 444-448. 